\title{
Key Points of the Japanese Society of Hypertension Guidelines for the Management of Hypertension in 2014
}

\author{
Kazuomi Kario \\ Division of Cardiovascular Medicine, Department of Medicine, Jichi Medical University \\ School of Medicine, Shimotsuke, Tochigi, Japan
}

\section{Key Words}

Japanese · Hypertension · Guideline

\begin{abstract}
The Japanese Society of Hypertension (JSH) published the new JSH guidelines for the management of hypertension in 2014, which is the revision of the JSH guidelines of 2009. The primary objective of the guideline is to provide physicians the standard treatment strategy of hypertension to prevent the hypertension-related target organ damage and cardiovascular events. The management of hypertension should be performed in hypertensive patients with a blood pressure of $\geq 140 / 90 \mathrm{~mm} \mathrm{Hg}$. As Asians have a higher prevalence of stroke than of coronary artery disease and stroke is more steeply associated with the level of blood pressure, the target blood pressure should be lower than $130 / 80 \mathrm{~mm} \mathrm{Hg}$ for high-risk patients such as those with diabetes or chronic kidney disease. Because of the increasing prevalence of obesity and the related metabolic syndrome, more salt intake and higher salt sensitivity in the population, lifestyle modifications are necessary in hypertensive patients and subjects with high normal blood pressure. This guideline provides evidence-based recommendations for the management of patients with hypertension with the characteristics of our society.
\end{abstract}

(c) 2015 S. Karger AG, Base

\section{Introduction}

The Japanese Society of Hypertension published the new guidelines 'The Japanese Society of Hypertension (JSH) Guidelines for the Management of Hypertension in 2014' (JSH2014GL), aiming at a more effective prevention of hypertension-related organ damage and cardiovascular events in consideration of Asian characteristics (fig. 1) [1-4], which are different from 
Fig. 1. Characteristics of hypertension in Asia [4].

Kario: Key Points of the Japanese Society of Hypertension Guidelines for the Management of Hypertension in 2014

\section{Stroke - more common than coronary artery disease}

\section{Steeper association between BP and stroke}

3. High salt intake with high salt sensitivity

4.Epidemic obesity and metabolic syndrome

\subsection{4-hr BP control - more important}

Western characteristics, i.e., stroke occurs more often than coronary artery disease, the slope of the association between blood pressure (BP) and stroke is steeper, salt intake and salt sensitivity are higher, the prevalence of obesity and the related metabolic syndrome is increasing, the prevalence of non-dippers is high and 24-hour BP control is more important.

\section{Making Process}

The JSH2014GL chose 40 writing members and 79 document reviewers who were officials of the JSH and specialists in stroke, pregnancy-induced hypertension, endocrinology, dementia, dialysis, and medical economics. In addition, 15 liaison members were consigned based on recommendations from 14 affiliated societies, and evaluation was performed according to AGREE II (Appraisal of Guidelines for Research and Evaluation II) [5]. Eight advisors were consigned.

A systematic review was conducted. The post-JSH2009GL literature from January 2009 until June 2013 was investigated in PubMed using the key words 'disease', 'target of blood pressure control', and 'selection of antihypertensive drugs', and this was adopted as the basis of the systematic review. The results of the reassessment of the JSH2009 and ESH/ESC 2009, as well as references from the NICE/BHS guidelines in 2011 and ESH/ESC 2013, [6, 7] were presented to each member to reinforce literature investigation.

The evidence level and recommendation grade are shown in tables $1-3$. With respect to the evidence level, epidemiological studies are high quality ones, but the evidence level is low (IVa) in the sense of intervention/treatment for hypertension. Therefore, for quotations that are not involved in the recommendation grade, E-Ia, Ib, II, and III were established, as presented in table 2 . When guidelines prepared by other societies or positional statements were quoted, they were regarded as literature and expressed as (GL) without establishing the evidence level (tables 3, 4).

\section{Measurement and Clinical Evaluation of BP}

The importance of BP control throughout $24 \mathrm{~h}$ including sleep and morning periods was highly stressed in the JSH2014GL [1] as well as in recently published Western and international guidelines [6, 7], but not in two other guidelines [8, 9]. Both home BP monitoring and ambulatory $\mathrm{BP}$ (ABP) monitoring (ABPM) as well as office $\mathrm{BP}$ are recommended to use complementarily for the diagnosis of hypertension (fig. 2; table 5). Especially home $\mathrm{BP}$ monitoring is recommended to be used in clinical practice as the first step. In previous studies, home and ABPs are more closely associated with organ damage and cardiovascular prognosis than office BP in both hypertensive and community-dwelling Asian subjects [1016]. 


\begin{tabular}{|c|c|c|}
\hline \multicolumn{3}{|c|}{ Pulse 2015;3:35-47 } \\
\hline \multicolumn{2}{|c|}{ DOI: $10.1159 / 000381300$} & $\begin{array}{l}\text { (c) } 2015 \text { S. Karger AG, Basel } \\
\text { www.karger.com/pls }\end{array}$ \\
\hline \multicolumn{3}{|c|}{$\begin{array}{l}\text { Kario: Key Points of the Japanese Society of Hypertension Guidelines for the } \\
\text { Management of Hypertension in } 2014\end{array}$} \\
\hline $\begin{array}{l}\text { Evidence } \\
\text { level }\end{array}$ & \multicolumn{2}{|c|}{ Classification } \\
\hline 1 & \multicolumn{2}{|c|}{$\begin{array}{l}\text { Systematic reviews, meta-analysis of randomized } \\
\text { comparative studies }\end{array}$} \\
\hline II & \multicolumn{2}{|c|}{ Randomized comparative studies } \\
\hline III & \multicolumn{2}{|c|}{$\begin{array}{l}\text { Non-randomized comparative studies, Subanalysis/ } \\
\text { retrospective analysis of randomized comparative } \\
\text { studies }\end{array}$} \\
\hline IVa & \multicolumn{2}{|c|}{$\begin{array}{l}\text { Epidemiological studies (cohort studies, meta-analysis of } \\
\text { cohort studies) }\end{array}$} \\
\hline $\mathrm{IVb}$ & \multicolumn{2}{|c|}{$\begin{array}{l}\text { Epidemiological studies (case-controlled studies, } \\
\text { cross-sectional studies) }\end{array}$} \\
\hline $\mathrm{V}$ & \multicolumn{2}{|c|}{ Descriptive studies (case reports, case series) } \\
\hline VI & \multicolumn{2}{|c|}{ Special committees' or specialists' opinions } \\
\hline
\end{tabular}

Table 1. Classification of the evidence level regarding treatment/diagnosis
Table 2. Classification of the evidence level of epidemiological studies regarding risk factors/ prognosis
Table 3. Recommendation grade described in POINT

Table 4. Rules for determining the recommendation grade

\begin{tabular}{ll}
\hline $\begin{array}{l}\text { Evidence } \\
\text { level }\end{array}$ & Classification \\
\hline E-Ia & Meta-analysis of cohort studies \\
E-Ib & Cohort studies \\
E-II & Case-controlled studies, cross-sectional studies \\
E-III & Descriptive studies (case series) \\
\hline
\end{tabular}

\section{Diagnosis/treatment items of POINT}

\begin{tabular}{ll} 
A & Strongly recommended based on strong scientific grounds \\
B & Recommended based on scientific grounds \\
C1 & Recommended despite insufficient scientific grounds \\
C2 & Not recommended despite insufficient scientific grounds \\
D & Not recommended based on scientific grounds \\
\hline
\end{tabular}

Important items were presented as POINT.

\section{Diagnosis/treatment items of POINT}

$\begin{array}{ll}\text { A } & \text { There are } \geq 1 \text { results at evidence level I (table 1) } \\ \text { B } & \text { There are } \geq 1 \text { results at evidence level II (table 1) } \\ \text { C1/2 } & \begin{array}{l}\text { based on the results at evidence level III, IV, V, or VI } \\ \text { (table } 1 \text { ) }\end{array} \\ \text { D } & \text { There are } \geq 1 \text { results at evidence level I or II (table 1) }\end{array}$

Consensus-based recommendation grade is expressed as 'consensus'. 
Kario: Key Points of the Japanese Society of Hypertension Guidelines for the Management of Hypertension in 2014

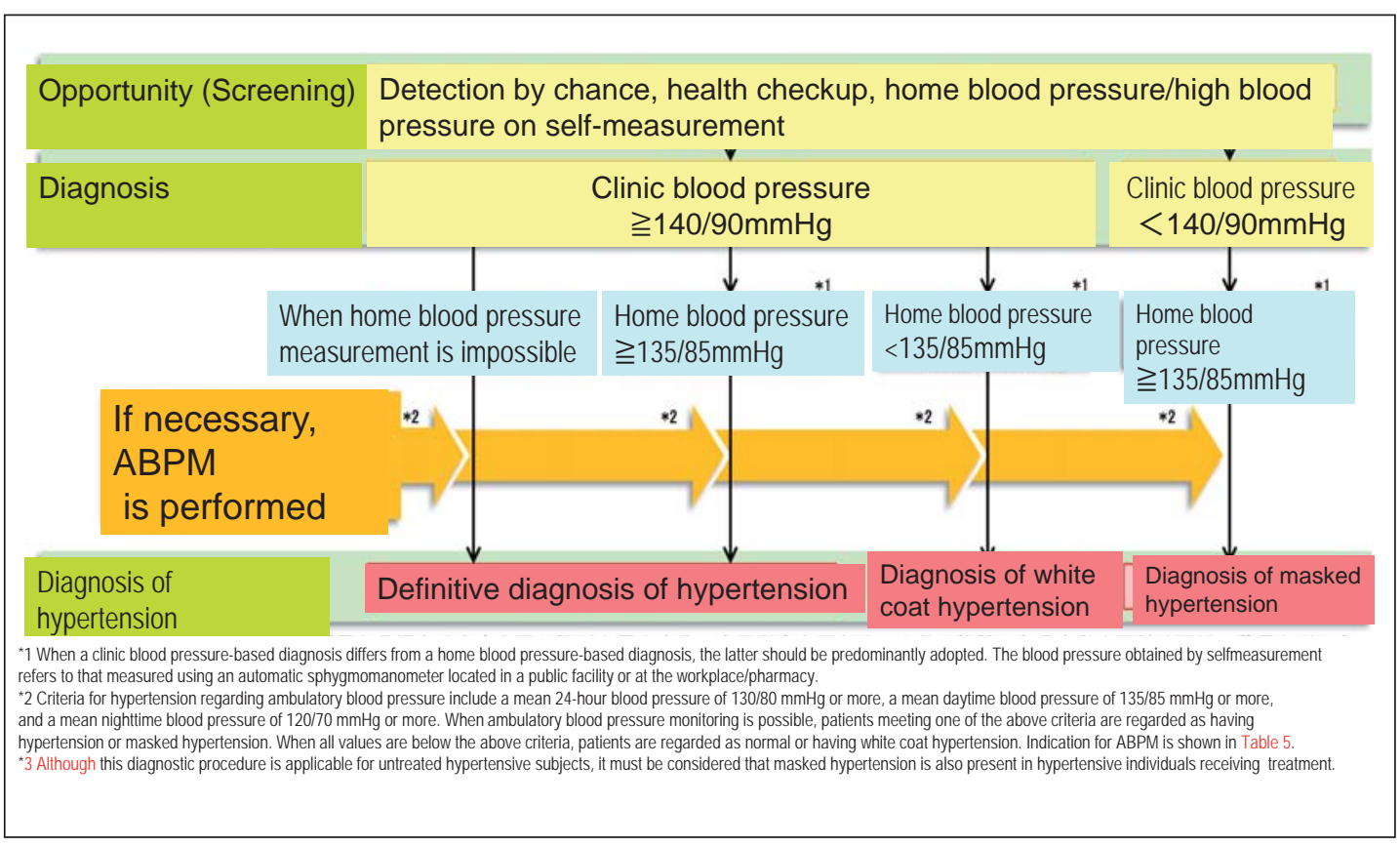

Fig. 2. BP measurement and procedure for hypertension diagnosis [1].

Table 5. Indications for ABPM

1 When a home BP fluctuates around 135/85 mm Hg or a clinic BP fluctuates around 140/90 mm Hg makes diagnosis of hypertension difficult.

2 When a high-normal value (125-134/80-84 mm Hg) is obtained on home BP measurement.

3 When there is marked variability in the home BP.

a. When a definitive diagnosis of white coat hypertension is not made based on the home BP level.

b. When a definitive diagnosis of masked hypertension is not made based on the home BP level.

c. When self-measurement of BP is impossible at the workplace and workplace hypertension is suspected.

d. When a definitive diagnosis of resistant hypertension is not made based on the home BP level.

e. When the nighttime BP is not measured on home BP and nocturnal hypertension (non-dipper, riser) is suspected.

$4 \quad$ When the information on short-term variability of BP is warranted.

a. When incidental, transient hypertension or hypotension is observed.

b. When the home and clinic BP levels markedly change.

When ABPM is possible in patients meeting one of the above indications, this should be performed if necessary.

Based on the discrepancy between the office and out-of office BPs, white coat hypertension and masked hypertension are diagnosed (fig. 3). Subtypes of masked hypertension are morning hypertension, nocturnal hypertension, and daytime hypertension (fig. 3). Morning hypertension and morning BP surge [17-24] as well as nocturnal hypertension and a riser pattern of nocturnal BP dipping [25-30] were demonstrated to be associated with cardiovascular risk in Asian studies.

\section{Key Points}

1. Clinic BP should be measured by maintaining the arm-cuff position at the heart level during rest in a seated position. The measurement must be performed two or more times 


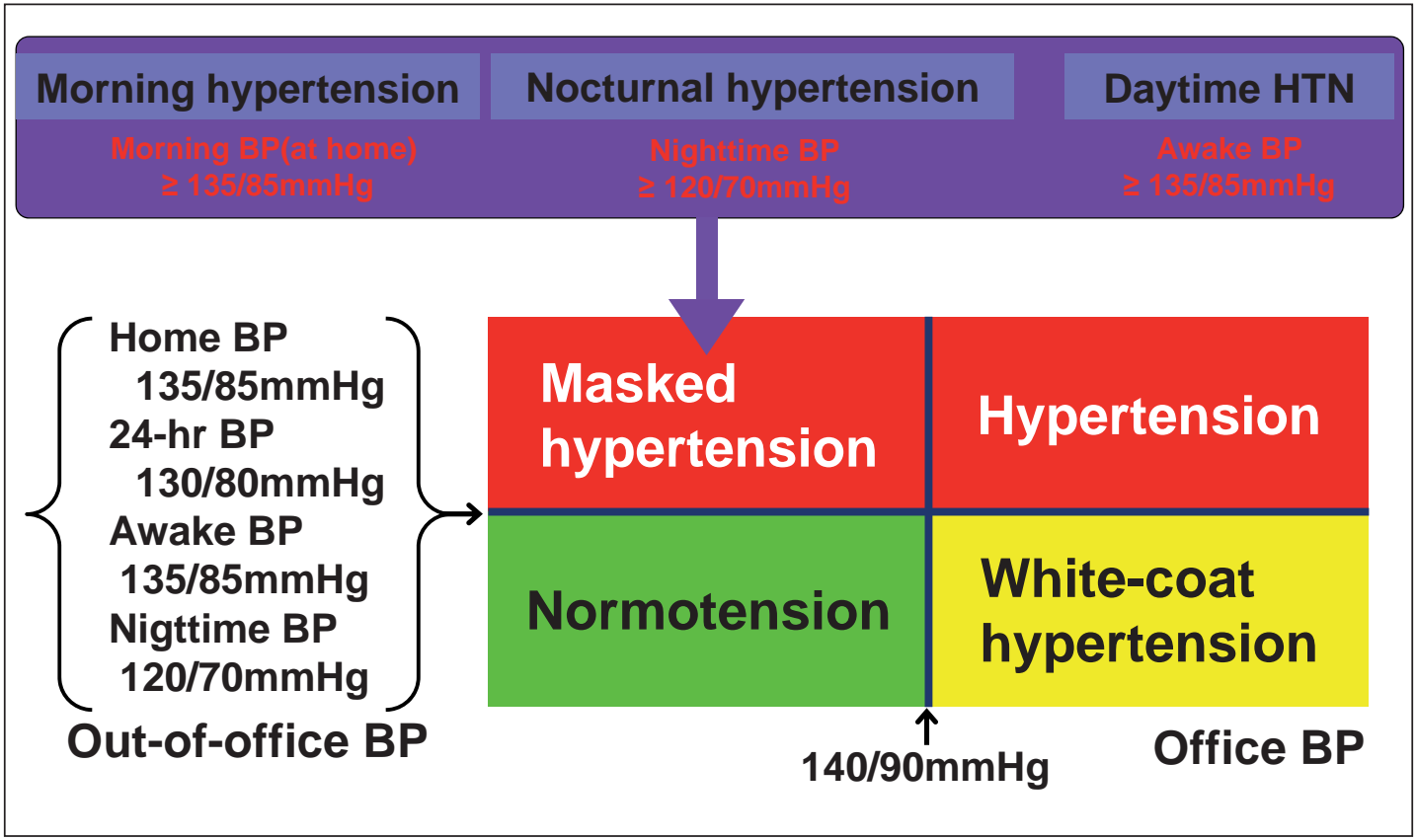

Fig. 3. Definition of white coat and masked hypertension.

at intervals of 1-2 min, and the mean value of two measurements that provide stable values (difference in the values: $<5 \mathrm{~mm} \mathrm{Hg}$ ) should be used. Diagnosis of hypertension should be based on clinic BP measured on at least two different occasions. (Evidence level: VI.)

2. Clinic BP is measured by the auscultation method using a mercury sphygmomanometer, which is the standard procedure, but the use of an automatic sphygmomanometer is also permitted. (Evidence level: VI.)

3. Home BP measurement and 24-hour ABPM are useful for the diagnosis of hypertension, white coat hypertension, and masked hypertension, as well as for evaluating the drug effect and its duration. (Evidence level: IVa, III.)

4. Home BP should be measured with upper-arm devices. As a rule, it must be determined twice, and the mean value should be used as a BP value on the occasion. If the measurement is performed only once, the BP level should be used as a value on the occasion. (Evidence level: VI.)

5. Criteria for hypertension differ among clinic BP, 24-hour ABP, and home BP. A clinic BP of $>140 / 90 \mathrm{~mm} \mathrm{Hg}$, a home BP of $>135 / 85 \mathrm{~mm} \mathrm{Hg}$, and a mean 24-hour ABP of $>130 / 80$ $\mathrm{mm} \mathrm{Hg}$ are regarded as indicators of hypertension. (Evidence level: E-Ia.)

6. When there is a discrepancy of diagnosis between clinic BP and home BP, a home BPbased diagnosis should have priority.

7. In treating hypertension, attention must also be given to the pattern of diurnal BP changes (non-dipper, riser, and dipper), nighttime BP, early-morning BP, and BP at the workplace. (Evidence level: E-Ib.)

White Coat Hypertension

1. Patients with a systolic clinic BP of $>140 \mathrm{~mm} \mathrm{Hg}$ and/or a diastolic BP of $>90 \mathrm{~mm} \mathrm{Hg}$ in whom systolic and diastolic home BPs are $<135$ and $<85 \mathrm{~mm} \mathrm{Hg}$, respectively, or the 
Kario: Key Points of the Japanese Society of Hypertension Guidelines for the

Management of Hypertension in 2014

mean 24-hour systolic and diastolic BPs on ABPM are $<130$ and $<80 \mathrm{~mm} \mathrm{Hg}$, respectively, are regarded as having white coat hypertension (fig. 3). (Evidence level: E-Ia.)

2. White coat hypertension is observed in $15-30 \%$ of hypertensive patients. In the elderly, the percentage increases. (Evidence level: E-II.)

3. White coat hypertension may deteriorate to hypertension and diabetes in the future. (Evidence level: E-Ib.)

Masked Hypertension

1. Patients with a mean systolic clinic BP of $<140 \mathrm{~mm} \mathrm{Hg}$ and a diastolic $\mathrm{BP}$ of $<90 \mathrm{~mm} \mathrm{Hg}$ who show a systolic home BP of $>135 \mathrm{mmHg}$ and/or a diastolic BP of $>85 \mathrm{~mm} \mathrm{Hg}$, or a mean 24-hour systolic BP of $>130 \mathrm{~mm} \mathrm{Hg}$ and/or a diastolic BP of $>80 \mathrm{~mm} \mathrm{Hg}$ on ABPM are regarded as having masked hypertension (fig. 3). (Evidence level: E-Ia.)

2. Masked hypertension is classified into three types: early-morning hypertension (earlymorning BP $\geq 135 / 85$ mm Hg), nocturnal hypertension (nighttime BP $\geq 120 / 70 \mathrm{~mm} \mathrm{Hg}$ ), and daytime hypertension (daytime $\mathrm{BP} \geq 135 / 85 \mathrm{~mm} \mathrm{Hg}$ ) (fig. 3). (Evidence level: E-la.)

3. Masked hypertension is observed in $10-15 \%$ of normotensive residents and in approximately $30 \%$ of hypertensive patients during antihypertensive therapy in whom systolic and diastolic BP levels are maintained at $<140 / 90 \mathrm{~mm} \mathrm{Hg}$. (Evidence level: E-II.)

4. The risk of cardiovascular morbidity from untreated masked hypertension is similar to that from persistent hypertension. Masked hypertension should be regarded as a subtype of hypertension. (Evidence level: E-Ia.)

\section{Principles of Treatment}

The management of hypertension in accordance with the JSH2014GL should be performed in hypertensive patients with a BP of $\geq 140 / 90 \mathrm{~mm} \mathrm{Hg}$. In those with diabetes mellitus and chronic kidney disease (CKD) complicated by proteinuria, in which the risk of stroke, heart disease, and renal failure is high, hypertension treatment must be conducted if BP is $\geq 130 / 80$ $\mathrm{mm} \mathrm{Hg}$. On the other hand, in hypertensive patients with metabolic syndrome, lifestyle modifications are necessary even in those with a high-normal BP (130-139/85-89 mm Hg). Even in normotensive patients, the prevention of hypertension through lifestyle modifications such as salt restriction, correction of obesity, and exercise is an important issue as a population strategy.

The most important difference between JSH2014GL and Western guidelines are the different target BP levels for high-risk patients with diabetes and/or CKD. Recently revised Western guidelines increased the target BP levels up to 140/90 mm Hg for these high-risk hypertensive patients [6-9]. As a characteristic of East Asian patients, the slope of the association between clinic BP level and stroke risk is steeper than that for Western patients [2-4]. In addition, as the phenotype of cardiovascular disease, stroke occurs more frequently than myocardial infarction $[3,4,16]$. Considering these Asian characteristics, in the JSH2014GL, the target BP levels remained at 130/80 mm Hg for high-risk hypertensive patients with diabetes and/or CKD with proteinuria (fig. 4). In addition, JSH2014GL recommended to achieve a home BP $<125 / 75 \mathrm{~mm}$ Hg for hypertensive patients with diabetes (fig. 4) because two studies demonstrated the benefits of patients who could achieve this level [31, 32].

Key Points

1. Antihypertensive treatment should be performed to prevent the occurrence of cardiovascular disease due to sustained high BP, progression, recurrence-related mortality, and a reduction in the quality of life. (Recommendation grade: A; evidence level: I.) 


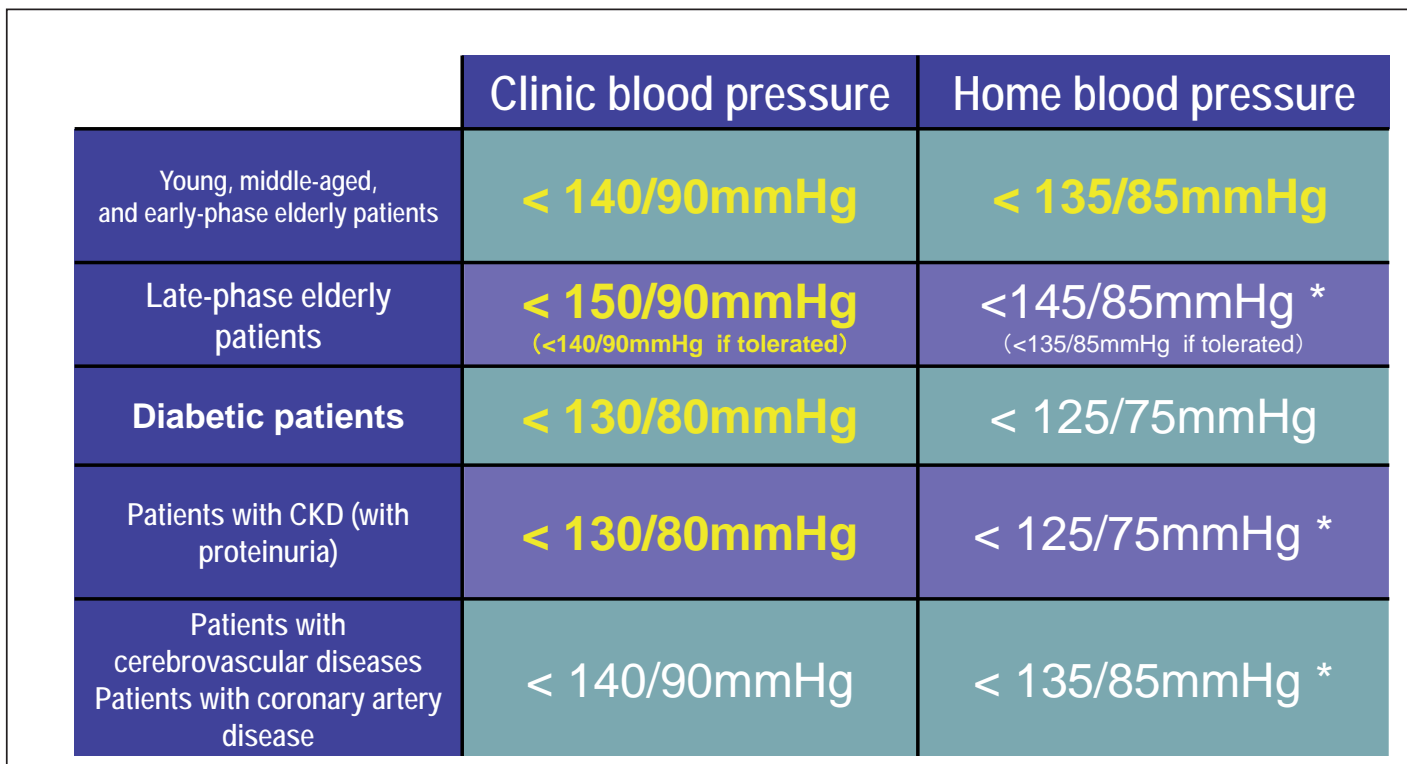

Clinic BP should be $<130 \mathrm{mmHg}$ in hypertensives with antiplatelet or anticoagulation therapy.

Fig. 4. Target levels of BP control (JSH 2014) [1].

2. Antihypertensive treatment should be indicated for all hypertensive patients with a BP of $>140 / 90 \mathrm{~mm} \mathrm{Hg}$. These patients are stratified into three groups: low-, moderate-, and high-risk based on the BP level, risk factors other than BP, and presence or absence of hypertensive organ damage.

3. Antihypertensive treatment consists of lifestyle modifications (step 1) and antihypertensive drug therapy (step 2). The starting point of this therapy should be determined based on the risk level of the individual patients.

4. The risk increases from the level of high-normal BP. Progression from high-normal BP to hypertension should be prevented by modifying the lifestyle. (Recommendation grade: B; evidence level: II.)

5. The goal of antihypertensive treatment is to reduce the BP to $<140 / 90 \mathrm{~mm} \mathrm{Hg}$. However, among diabetic and CKD patients with proteinuria, treatment should be performed in those with a BP of $>130 / 80 \mathrm{~mm} \mathrm{Hg}$. The target BP is $<130 / 80 \mathrm{~mm} \mathrm{Hg}$. In late-phase elderly hypertensive patients, the target $\mathrm{BP}$ is $<150 / 90 \mathrm{~mm} \mathrm{Hg}$. If tolerance is present, a $\mathrm{BP}$ of $<140 / 90 \mathrm{~mm} \mathrm{Hg}$ should be targeted. (Recommendation grade: A; evidence level: I.)

6. In principle, antihypertensive drug therapy should be started with a low dose of a longacting drug once a day. If the dose must be increased, twice-daily administration may be considered. Appropriate combination therapy with antihypertensive drugs should be conducted to prevent adverse effects and enhance antihypertensive effects. Combination therapy should be considered from the outset for grade II or more severe hypertension. (Recommendation grade: B; consensus; evidence level: III.)

7. Reducing the number of tablets and frequency of dosing is useful for improving adherence. (Recommendation grade: A; evidence level: I.)

8. Home BP measurement is useful not only for the diagnosis of white coat hypertension and masked hypertension, but also for evaluating the antihypertensive effects or improving patients' adherence/concordance. (Recommendation grade: A; evidence level: I.) 
Kario: Key Points of the Japanese Society of Hypertension Guidelines for the

Management of Hypertension in 2014

9. Sufficient communication, information, and considerations for quality of life/adverse effects are useful for improving adherence, achieving better BP control, and preventing cardiovascular disease. (Recommendation grade: B; consensus; evidence level: IVa.)

10. For treatment, the attending physician must eventually determine a therapeutic strategy after establishing concordance involving the results of epidemiological and clinical studies, clinical background of the patient, pharmacological actions of antihypertensive drugs, health expenditure, and cost-effectiveness. (Recommendation grade: C1; evidence level: VI.)

\section{Lifestyle Modifications}

Asian subjects are likely to have a high salt intake with high salt sensitivity [4, 33]. Thus, salt restriction should be more effective in Asian patients than in Western patients.

\section{Key Points}

1. Lifestyle modifications are important for preventing hypertension as well as before and after the start of antihypertensive drug therapy. (Recommendation grade: A; consensus.)

2. Salt reduction: the target of salt reduction is $<6 \mathrm{~g} /$ day. (Recommendation grade: A; evidence level: I.)

3. Dietary pattern: fruit/vegetable intake should be increased, and cholesterol/saturated fatty acid intake should be reduced. Fish (fish oil) intake should also be increased. (Recommendation grade: B; evidence level: II.)

4. Weight control: the target body mass index (BMI) is $<25$. Even when the target is not reached, a significant decrease in BP can be achieved by reducing body weight by approximately 4 kg. (Recommendation grade: A; evidence level: I.)

5. Exercise: primarily periodic ( $\geq 30 \mathrm{~min}$ daily if possible) and aerobic exercise should be practiced. (Recommendation grade: A; evidence level: I.)

6. Reduction of alcohol intake: alcohol intake should be restricted. (Recommendation grade: A; evidence level: I.)

7. Quitting smoking: smoking cessation should be promoted, and passive smoking must be avoided. (Recommendation grade: A; consensus; evidence level: IVa.)

8. Others: exposure to cold temperatures should be avoided. Emotional stress should be managed. (Recommendation grade: $\mathrm{C} 1$; evidence level: IVa.)

9. Comprehensive lifestyle modifications are more effective. (Recommendation grade: B; evidence level: II.)

\section{Treatment with Antihypertensive Drugs}

The JSH2014GL again stressed that BP lowering per se is more important than the different classes of antihypertensives. A recent meta-analysis of Asian clinical trials supported this statement [34]. The JSH2014GL separately used the words 'major antihypertensive drugs' and 'first-line drugs' and defined 'first-line drugs' as those that could be used in patients without any compelling indications. The major drugs included beta blockers; however, beta blockers are excluded from the first-line drugs.

Compelling indications are shown in figure 5. The RAS inhibitor is recommended to be used as the first-line drug for high-risk hypertensive patients with diabetes and/or CKD with albuminuria $[35,36]$. The procedures of hypertension treatment in the absence of compelling indications are shown in figure 6. To achieve a target BP level, the combination of drugs are 
Kario: Key Points of the Japanese Society of Hypertension Guidelines for the Management of Hypertension in 2014

\begin{tabular}{|c|c|c|c|c|}
\hline & $\begin{array}{c}\text { Ca } \\
\text { antagonist }\end{array}$ & $\begin{array}{l}\text { ARB/ACE } \\
\text { inhibitor }\end{array}$ & diuretics & Bblocker \\
\hline LVH & O & O & & \\
\hline Heart failure & & 0 & 0 & $* 1$ \\
\hline Tachycardia & (nonDHP) & & & 0 \\
\hline Agina pectoris & O & & & $* 2$ \\
\hline Old Ml & & 0 & & 0 \\
\hline Proteinuria - & 0 & 0 & 0 & \\
\hline Proteinuria+ & & 0 & & \\
\hline Chronic stroke & $\overline{0}$ & $\overline{0}$ & $\overline{0}$ & \\
\hline Diabetes/MetS *3 & & 0 & & \\
\hline Osteoporosis & & & (thiazide) & \\
\hline $\begin{array}{l}\text { Aspiration } \\
\text { pneumonia }\end{array}$ & & $O(A C E-I)$ & & \\
\hline
\end{tabular}

Fig. 5. Compelling indications [1].

\begin{tabular}{|c|c|}
\hline & Hypertension without compelling indications \\
\hline STEP 1 & One of $A, C$, and D*1 \\
\hline STEP 2 & One of $A+C, A+D$, and $C+D$ \\
\hline STEP 3 & $\begin{array}{c}A+C+D \\
\downarrow\end{array}$ \\
\hline STEP 4 & $\begin{array}{l}\text { Resistant hypertension } \\
\text { A+C+D+ } \beta-\text { or } \alpha \text {-blockers, aldosterone antagonists, } \\
\text { and other types of antihypertensive drugs }\end{array}$ \\
\hline $\begin{array}{l}\text { First-choice } \\
\text { drugs }\end{array}$ & $\begin{array}{l}\text { A: ARBs, ACE inhibitors,C: Ca channel blockers, } \\
\text { D: Thiazide diuretics, thiazide analogues, }\end{array}$ \\
\hline
\end{tabular}

Fig. 6. Procedures of hypertension treatment in the absence of compelling indications [1]. 


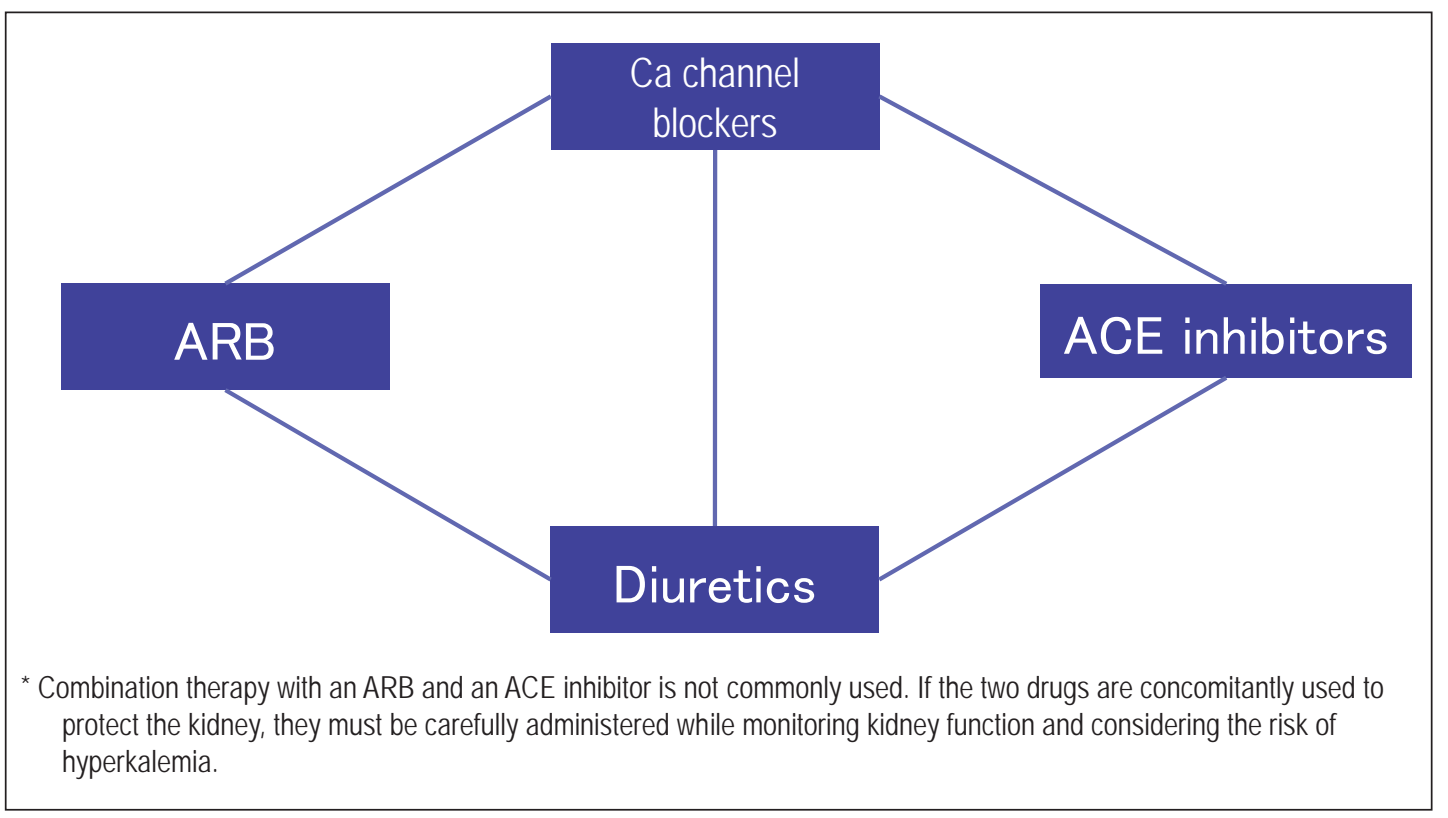

Fig. 7. Combination of two drugs [1].

recommended [37-39]; however, the combination of 2 RAS inhibitors [angiotensin-receptor blockers (ARBs) and angiotensin-converting enzyme (ACE) inhibitors] is not recommended (fig. 7).

\section{Key Points}

1. The preventive effects of antihypertensive drugs on cardiovascular disease are determined by the degree to which BP decreases rather than its class. (Recommendation grade: A; evidence level: I.)

2. Appropriate antihypertensive drugs should be selected considering compelling indications, contraindications, conditions that require the careful use of drugs and the presence or absence of complications. (Recommendation grade: B; evidence level: II.)

3. In hypertensive patients without compelling indications, the antihypertensive drug to be first administered should be selected from Ca channel blockers, ARBs, ACE inhibitors, and diuretics. (Recommendation grade: A; evidence level: I.)

4. Antihypertensive drugs are administered once a day, in principle, but as it is more important to control the BP over $24 \mathrm{~h}$, splitting the dose into twice a day is desirable in some situations. (Recommendation grade: C1; evidence level: III.)

5. A gradual reduction in BP is desirable in hypertensive patients in general, but the target control level should be achieved within several weeks in high-risk patients, such as those with grade III hypertension and multiple risk factors. (Recommendation grade: C1; evidence level: III.)

6. The use of two or three drugs in combination is often necessary to achieve the target of BP control. (Recommendation grade: A; evidence level: I.)

7. Combination therapy with different classes of antihypertensive drug exhibits potent hypotensive effects and is useful for achieving the target of BP control. (Recommendation grade: A; evidence level: I.) 
Kario: Key Points of the Japanese Society of Hypertension Guidelines for the Management of Hypertension in 2014

8. Among the combinations of two drugs, those of a renin-angiotensin (RA) system inhibitor (ACE inhibitor or ARB) + Ca channel blocker, RA system inhibitor + diuretic, and Ca channel blocker + diuretic are recommended. (Recommendation grade: B; evidence level: II.)

9. Simplification of the prescription using fixed-combination drugs is useful for improving adherence and controlling BP. (Recommendation grade: A; evidence level: I.)

\section{Disclosure Statement}

The author has no conflicts of interest to declare.

\section{References}

1 Shimamoto K, Ando K, Fujita T, et al; Japanese Society of Hypertension Committee for Guidelines for the Management of Hypertension: The Japanese Society of Hypertension Guidelines for the Management of Hypertension (JSH 2014). Hypertens Res 2014;37:253-387.

-2 Lawes CM, Bennett DA, Parag V, Woodward M, Whitlock G, Lam TH, Suh I, Rodgers A; Asia Pacific Cohort Studies Collaboration: Blood pressure indices and cardiovascular disease in the Asia Pacific region: a pooled analysis. Hypertension 2003;42:69-75.

-3 Ueshima H, Sekikawa A, Miura K, Turin TC, Takashima N, Kita Y, Watanabe M, Kadota A, Okuda N, Kadowaki T, Nakamura Y, Okamura T: Cardiovascular disease and risk factors in Asia: a selected review. Circulation 2008;118:2702-2709.

-4 Kario K: Proposal of a new strategy for ambulatory blood pressure profile-based management of resistant hypertension in the era of renal denervation. Hypertens Res 2013;36:478-484.

5 Brouwers M, Kho ME, Browman GP, Burgers JS, Cluzeau F, Feder G, Fervers B, Graham ID, Grimshaw J, Hanna S, Littlejohns P, Makarski J, Zitzelsberger L; AGREE Next Steps Consortium: AGREE II: Advancing guideline development, reporting and evaluation in healthcare. Can Med Assoc J 2010;182:E839-E842.

6 Krause T, Lovibond K, Caulfield M, McCormack T, Williams B; Guideline Development Group: Management of hypertension: summary of NICE guidance. BMJ 2011;343:d4891.

7 Mancia G, Fagard R, Narkiewicz K, Redón J, Zanchetti A, Böhm M, Christiaens T, Cifkova R, De Backer G, Dominiczak A, Galderisi M, Grobbee DE, Jaarsma T, Kirchhof P, Kjeldsen SE, Laurent S, Manolis AJ, Nilsson PM, Ruilope LM, Schmieder RE, Sirnes PA, Sleight P, Viigimaa M, Waeber B, Zannad F; Task Force Members: 2013 ESH/ESC Guidelines for the management of arterial hypertension: the Task Force for the management of arterial hypertension of the European Society of Hypertension (ESH) and of the European Society of Cardiology (ESC). J Hypertens 2013;31:1281-1357.

8 Weber MA, Schiffrin EL, White WB, Mann S, Lindholm LH, Kenerson JG, Flack JM, Carter BL, Materson BJ, Ram CV, Cohen DL, Cadet JC, Jean-Charles RR, Taler S, Kountz D, Townsend RR, Chalmers J, Ramirez AJ, Bakris GL, Wang J, Schutte AE, Bisognano JD, Touyz RM, Sica D, Harrap SB: Clinical practice guidelines for the management of hypertension in the community: a statement by the American Society of Hypertension and the International Society of Hypertension. J Clin Hypertens 2014;16:14-26.

$\rightarrow 9$ James PA, Oparil S, Carter BL, Cushman WC, Dennison-Himmelfarb C, Handler J, Lackland DT, LeFevre ML, MacKenzie TD, Ogedegbe O, Smith SC Jr, Svetkey LP, Taler SJ, Townsend RR, Wright JT Jr, Narva AS, Ortiz E: 2014 evidence-based guideline for the management of high blood pressure in adults: report from the panel members appointed to the Eighth Joint National Committee (JNC 8). JAMA 2014;311:507-520.

10 Kario K: Essential Manual of 24-Hour Blood Pressure Management from Morning to Nocturnal Hypertension. London, Wiley-Blackwell, 2015, pp 1-138.

11 Imai Y, Ohkubo T, Sakuma M, Tsuji II, Satoh H, Nagai K, Hisamichi S, Abe K: Predictive power of screening blood pressure, ambulatory blood pressure and blood pressure measured at home for overall and cardiovascular mortality: a prospective observation in a cohort from Ohasama, northern Japan. Blood Press Monit 1996;1: 251-254.

12 Kario K, Shimada K, Schwartz JE, Matsuo T, Hoshide S, Pickering TG: Silent and clinically overt stroke in older Japanese subjects with white-coat and sustained hypertension. J Am Coll Cardiol 2001;38:238-245.

13 Ohkubo T, Kikuya M, Metoki H, Asayama K, Obara T, Hashimoto J, Totsune K, Hoshi H, Satoh H, Imai Y: Prognosis of "masked" hypertension and "white-coat" hypertension detected by 24-h ambulatory blood pressure monitoring 10-year follow-up from the Ohasama study. J Am Coll Cardiol 2005;46:508-515.

14 Asayama K, Ohkubo T, Metoki H, Obara T, Inoue R, Kikuya M, Thijs L, Staessen JA, Imai Y; Hypertension Objective Treatment Based on Measurement by Electrical Devices of Blood Pressure (HOMED-BP): Cardiovascular outcomes in the first trial of antihypertensive therapy guided by self-measured home blood pressure. Hypertens Res 2012;35:1102-1110. 
Kario: Key Points of the Japanese Society of Hypertension Guidelines for the Management of Hypertension in 2014

15 Kario K, Saito I, Kushiro T, Teramukai S, Ishikawa Y, Mori Y, Kobayashi F, Shimada K: Home blood pressure and cardiovascular outcomes in patients during antihypertensive therapy: primary results of HONEST, a large-scale prospective, real-world observational study. Hypertension 2014;64:989-996.

-16 Wei FF, Li Y, Zhang L, Xu TY, Ding FH, Staessen JA, Wang JG: Association of target organ damage with 24-hour systolic and diastolic blood pressure levels and hypertension subtypes in untreated Chinese. Hypertension 2014;63:222-228.

17 Kario K, Pickering TG, Umeda Y, Hoshide S, Hoshide Y, Morinari M, Murata M, Kuroda T, Schwartz JE, Shimada $\mathrm{K}$ : Morning surge in blood pressure as a predictor of silent and clinical cerebrovascular disease in elderly hypertensives: a prospective study. Circulation 2003;107:1401-1406.

18 Kario K: Clinician's Manual on Early Morning Risk Management in Hypertension. London, Science Press, 2004, pp 1-68.

-19 Kario K, Ishikawa J, Pickering TG, Hoshide S, Eguchi K, Morinari M, Hoshide Y, Kuroda T, Shimada K: Morning hypertension: the strongest independent risk factor for stroke in elderly hypertensive patients. Hypertens Res 2006;29:581-587.

20 Kario K: Morning surge in blood pressure and cardiovascular risk: evidence and perspectives. Hypertension 2010;56:765-773.

-21 Metoki H, Ohkubo T, Kikuya M, Asayama K, Obara T, Hashimoto J, Totsune K, Hoshi H, Satoh H, Imai Y: Prognostic significance for stroke of a morning pressor surge and a nocturnal blood pressure decline: the Ohasama study. Hypertension 2006;47:149-154.

-22 Chen CT, Li Y, Zhang J, Wang Y, Ling HW, Chen KM, Gao PJ, Zhu DL: Association between ambulatory systolic blood pressure during the day and asymptomatic intracranial arterial stenosis. Hypertension 2014;63:61-67.

-23 Hoshide S, Kario K, Yano Y, Haimoto H, Yamagiwa K, Uchiba K, Nagasaka S, Matsui Y, Nakamura A, Fukutomi M, Eguchi K, Ishikawa J; the J-HOP study group: Association of morning and evening blood pressure at home with asymptomatic organ damage in the J-HOP Study. Am J Hypertens 2014;27:939-947.

24 Kario K: Prognosis in relation to blood pressure variability: pro. Hypertension 2015, in press.

25 Kario K, Matsuo T, Kobayashi H, Imiya M, Matsuo M, Shimada K: Nocturnal fall of blood pressure and silent cerebrovascular damage in elderly hypertensive patients. Advanced silent cerebrovascular damage in extreme dippers. Hypertension 1996;27:130-135.

26 Kario K, Pickering TG, Matsuo T, Hoshide S, Schwartz JE, Shimada K: Stroke prognosis and abnormal nocturnal blood pressure falls in older hypertensives. Hypertension 2001;38:852-857.

27 Ohkubo T, Hozawa A, Yamaguchi J, Kikuya M, Ohmori K, Michimata M, Matsubara M, Hashimoto J, Hoshi H, Araki T, Tsuji I, Satoh H, Hisamichi S, Imai Y: Prognostic significance of the nocturnal decline in blood pressure in individuals with and without high 24-h blood pressure: the Ohasama study. J Hypertens 2002;20:21832189.

-28 Hoshide S, Ishikawa J, Eguchi K, Ojima T, Shimada K, Kario K: Masked nocturnal hypertension and target organ damage in hypertensives with well-controlled self-measured home blood pressure. Hypertens Res 2007;30: 143-149.

29 Li Y, Staessen JA, Lu L, Li LH, Wang GL, Wang JG: Is isolated nocturnal hypertension a novel clinical entity? Findings from a Chinese population study. Hypertension 2007;50:333-339.

-30 Kario K, Hoshide S, Haimoto H, Yamagiwa K, Uchiba K, Nagasaka S, Yano Y, Eguchi K, Matsui Y, Shimizu M, Ishikawa J, Ishikawa S; the J-HOP study group: Sleep blood Pressure self-measured at home as a novel determinant of organ damage: Japan Morning Surge Home Blood Pressure (J-HOP) Study. J Clin Hypertens (Greenwich) 2015;17:340-348.

-31 Noguchi Y, Asayama K, Staessen JA, Inaba M, Ohkubo T, Hosaka M, Satoh M, Kamide K, Awata T, Katayama S, Imai Y; the HOMED-BP study group. Predictive power of home blood pressure and clinic blood pressure in hypertensive patients with impaired glucose metabolism and diabetes. J Hypertens 2013;31:1593-1602.

-32 Eguchi K, Hoshide S, Ishikawa S, Shimada K, Kario K: Aggressive blood pressure-lowering therapy guided by home blood pressure monitoring improves target organ damage in hypertensive patients with type 2 diabetes/ prediabetes. J Clin Hypertens (Greenwich) 2012;14:422-428.

-33 Tsuchihashi T, Kai H, Kusaka M, Kawamura M, Matsuura H, Miura K, Ando K, Maruyama S, Hayabuchi H, Takagi Y, Nakahigashi N, Sato T, Kawano Y: [Scientific Statement] Report of the Salt Reduction Committee of the Japanese Society of Hypertension (3) Assessment and application of salt intake in the management of hypertension. Hypertens Res 2013;36:1026-1031.

-34 Yano Y, Briasoulis A, Bakris GL, Hoshide S, Wang JG, Shimada K, Kario K: Effects of antihypertensive treatment in Asian populations: a meta-analysis of prospective randomized controlled studies (CARdiovascular protectioN group in Asia: CARNA). J Am Soc Hypertens 2014;8:103-116.

35 Makino H, Haneda M, Babazono T, Moriya T, Ito S, Iwamoto Y, Kawamori R, Takeuchi M, Katayama S; INNOVATION Study Group. Prevention of transition from incipient to overt nephropathy with telmisartan in patients with type 2 diabetes. Diabetes Care 2007;30:1577-1578.

-36 Saruta T, Hayashi K, Ogihara T, Nakao K, Fukui T, Fukiyama K; CASE-J Study Group. Effects of candesartan and amlodipine on cardiovascular events in hypertensive patients with chronic kidney disease: subanalysis of the CASE-J Study. Hypertens Res 2009;32:505-512.

37 Matsui Y, Eguchi K, O’Rourke MF, Ishikawa J, Miyashita H, Shimada K, Kario K: Differential effects between a calcium channel blocker and a diuretic when used in combination with angiotensin II receptor blocker on central aortic pressure in hypertensive patients. Hypertension 2009;54:716-723. 
Kario: Key Points of the Japanese Society of Hypertension Guidelines for the Management of Hypertension in 2014

-38 Kario K: Proposal of RAS-diuretic versus RAS-calcium antagonist strategies in high-risk hypertension: insight from the 24-h ambulatory blood pressure profile and central pressure. J Am Soc Hypertens 2010;4: 215-218.

-39 Ogihara T, Matsuzaki M, Umemoto S, Rakugi H, Matsuoka H, Shimada K, Higaki J, Ito S, Kamiya A, Suzuki H, Ohashi Y, Shimamoto K, Saruta T; Combination Therapy of Hypertension to Prevent Cardiovascular Events Trial Group: Combination therapy for hypertension in the elderly: a sub-analysis of the Combination Therapy of Hypertension to Prevent Cardiovascular Events (COPE) Trial. Hypertens Res 2012;35:441448. 